\title{
Effects of Aspirin on Endothelial Function and Hypertension
}

\author{
Mikhail S. Dzeshka ${ }^{1,2}$ • Alena Shantsila ${ }^{1}$ Gregory Y. H. Lip ${ }^{1,3}$ \\ Published online: 27 October 2016 \\ (C) The Author(s) 2016. This article is published with open access at Springerlink.com
}

\begin{abstract}
Purpose of review Endothelial dysfunction is intimately related to the development of various cardiovascular diseases, including hypertension, and is often used as a target for pharmacological treatment. The scope of this review is to assess effects of aspirin on endothelial function and their clinical implication in arterial hypertension.

Recent findings Emerging data indicate the role of platelets in the development of vascular inflammation due to the release of proinflammatory mediators, for example, triggered largely by thromboxane. Vascular inflammation further promotes oxidative stress, diminished synthesis of vasodilators, proaggregatory and procoagulant state. These changes translate into vasoconstriction, impaired circulation and thrombotic complications. Aspirin inhibits thromboxane synthesis, abolishes platelets activation and acetylates enzymes switching them to the synthesis of anti-inflammatory substances.

Summary Aspirin pleiotropic effects have not been fully elucidated yet. In secondary prevention studies, the decrease in cardiovascular events with aspirin outweighs bleeding risks, but this is not the case in primary prevention settings. Ongoing trials will provide more evidence on whether to expand the use of aspirin or stay within current recommendations.
\end{abstract}

This article is part of the Topical Collection on Antihypertensive Agents: Mechanisms of Drug Action

Gregory Y. H. Lip

g.y.h.lip@bham.ac.uk

1 University of Birmingham Institute of Cardiovascular Sciences, City Hospital, Dudley Road, Birmingham B18 7QH, UK

2 Grodno State Medical University, Grodno, Belarus

3 Aalborg Thrombosis Research Unit, Department of Clinical Medicine, Aalborg University, Aalborg, Denmark
Keywords Aspirin · Endothelial function · Arterial hypertension $\cdot$ Cyclooxygenase $\cdot$ Platelets $\cdot$ Inflammation

\section{Introduction}

Endothelium is of paramount importance for maintaining homeostasis of cardiovascular system [1]. Healthy endothelium, both in vasculature and heart chambers, is continuously releasing plethora of bioactive substances. Acting in autocrine, paracrine and systemic fashion and participating in regulation of smooth muscle contractions, vascular wall permeability, platelet aggregation, activation of coagulation and fibrinolytic activity, cellular proliferation, as well as in prevention of inflammatory cells adhesion and vascular inflammation. Imbalance between any of above functions is broadly defined as endothelial dysfunction. To the different extent, most cardiovascular diseases are classically attributed to endothelial dysfunction (from atherosclerotic heart disease to rhythm disturbances, e.g. atrial fibrillation) [2-4].

Given that endothelium takes part in regulation of vascular tone, arterial hypertension and endothelial function are reciprocally and intimately associated with each other. However, this association is far beyond simple imbalance between vasodilator and vasoconstrictor release in favour of the latter. Multiple mechanisms are involved in regulation of blood pressure, including the endothelium, kidneys and central regulation [5].

Of note, the endothelium does not only provide short-term effects on vascular tone. Endothelial dysfunction also has chronic long-term consequences, which, in indirect way, eventually have major impact on vascular remodelling and blood pressure regulation. Oxidative stress, i.e. production of free radicals outweighing their scavenging, is one of the systemic pathological processes, related to endothelium. 
Inflammation in the vascular wall is another example, synthesis of pro-inflammatory cytokines and recruitment of inflammatory cells, with hypertension being considered even as inflammatory disease now $[5,6]$.

Endothelial function has been extensively used as putative target for pharmacological correction with drugs inhibiting renin-angiotensin-aldosterone system, statins, antioxidants and so on, but less attention was paid to vascular effects of aspirin (i.e. acetylsalicylic acid) given its primary antiaggregatory mechanism of action. However, with the emerging evidence on role of platelets in inflammatory reactions and immunomodulation, platelet inhibition with aspirin has been found to also elicit also anti-inflammatory effects [7, 8, 9•, 10]. Moreover, aspirin was found to work as acetylating agent with a range of beneficial effects on vascular endothelium beyond platelet inhibition.

With regard to the possible effects of aspirin on blood pressure and management of arterial hypertension, these will be discussed in this review article.

\section{Brief Overview of Aspirin Pharmacology: Inhibition of Cyclooxygenase-1}

Aspirin has been used for years as analgesic, antipyretic and anti-inflammatory drug due to non-selective cyclooxygenase (COX)-1 and COX-2 inhibition (historically at high doses). Later, the major indication for aspirin shift to prevention of thrombotic cardiovascular complications as anti-platelet drug via predominant COX-1 inhibition within platelets, achievable at low doses.

Cyclooxygenases are present in the endothelial cells and tissues in two isoforms: COX-1 is considered to be a constitutively expressed enzyme, assuring physiological functions while COX-2 isoform is thought to carry potential for inducibility, but it is expressed constitutively at lower levels too. Cyclooxygenases are also defined as prostaglandin endoperoxide synthases or prostaglandin $(\mathrm{Pg}) \mathrm{G} / \mathrm{H}$ synthases since first $\mathrm{PgG}_{2}$ is synthesised from the arachidonic acid by incorporation of oxygen molecules, then $\mathrm{PgH}_{2}$ is formed by reduction of $\mathrm{PgG}_{2} \cdot \mathrm{PgH}_{2}$ is a substrate for enzymes, which via isomerisation, reduction or other transformations produce range of prostanoids. For example, thromboxane $\mathrm{A}_{2}\left(\mathrm{Tx}_{2}\right)$ is synthesised by $\mathrm{TxA}_{2}$ synthase (TXAS) and prostacyclin $\left(\mathrm{PgI}_{2}\right)$ is synthesised by prostacyclin synthase (PGIS) [11].

These inhibitory effects of aspirin are determined by presence of acetyl group that leads to acetylation of serine hydroxyl group at position 529 in COX-1 with eventual irreversible inhibition of the enzyme activity due to its inability to bind to substrate, arachidonic acid. Inhibition of platelet-dependent synthesis of $\mathrm{TxA}_{2}$ is accompanied by diminished release of platelets granules, numerous chemokines, growth factors and coagulation factors (Fig. 1) [7, 9•].
Many other 'pleiotropic' favourable effects of aspirin, which are not directly related to inhibition of $\mathrm{TxA}_{2}$ synthesis, are attributed to acetylation of target proteins. Their total number is far beyond half a thousand molecular targets, including transcription factors, enzymes, genes, metabolites and so on $[12,13 \cdot 14]$.

The maximal plasma concentration of aspirin reaches $1 \mathrm{mg} / \mathrm{L}$ within half an hour for aspirin $100 \mathrm{mg}$ taken orally and $3 \mathrm{mg} / \mathrm{L}$ for aspirin $300 \mathrm{mg}$ taken orally. These doses do not inhibition of COX-2 with COX-1 inhibition being the net pharmacological effect $[8,15]$. Because of irreversible action of aspirin (i.e. acetylation), duration of its effects is determined by target protein resynthesis, that in case of mature platelets lacking nuclei is equal to their lifetime (approximately 1 week). New platelets are needed in circulation to recover $\mathrm{TxA}_{2}$ synthesis. The endothelial effects of aspirin are more short lived as only few hours are required for endothelial cells to restore their capacity for COX-1 regeneration [8].

\section{Thromboxane $A_{2}$ and Prostacyclin in Platelets and Vasculature}

Thromboxane $A_{2}$ is synthesised via common pathway with other prostanoids and is largely deposited in platelets, although the non-platelet sources (e.g. leukocytes, endothelial cells) exist (Fig. 1). Effects of $\mathrm{TxA}_{2}$ are mainly local and realised in autocrine (i.e. platelet activation) and paracrine (e.g. on endothelial cells, leukocytes and so on) manner rather than systemic [8, 10, 11, 16, 17]. Multiple biological effects of $\mathrm{TxA}_{2}$ are due to binding of $\mathrm{TxA}_{2}$ prostanoid (TP) receptors, which are widely expressed in human body, including platelets, endothelium and smooth muscle cells in vasculature and myocardium [16]. Genetic polymorphism of TP receptors may result in their hypo- or hyperreactivity [18]. Expression of TP receptors on the cellular surface is enhanced in various cardiovascular diseases. For example, in vessels affected by atherosclerosis, there is a 3-fold increase of TP receptors density observed [19].

Activation of TP receptors on platelets leads to platelet activation and further amplification of $\mathrm{TxA}_{2}$ synthesis and release. Moreover, platelets $\alpha$-granule content is released to the blood flow that is represented by a multitude of biologically active molecules including coagulation, proinflammatory and growth factors, adhesive receptors and so on (Fig. 1). Following their release, these factors induce leukocytes recruitment, formation of heterotypic aggregates (platelets-leukocytes), promote inflammation, oxidative stress and remodelling of the vascular wall [7, 9•, 20-22].

Oxidative stress is prominent in cardiovascular diseases including hypertension, and it typically leads to reduced NO bioavailability and NO-dependent relaxation (Fig. 1) [23, 24]. Oxidative stress stimulates $\mathrm{TxA}_{2}$ pathway by TXAS upregulation and reduced degradation of the immature form of TP 


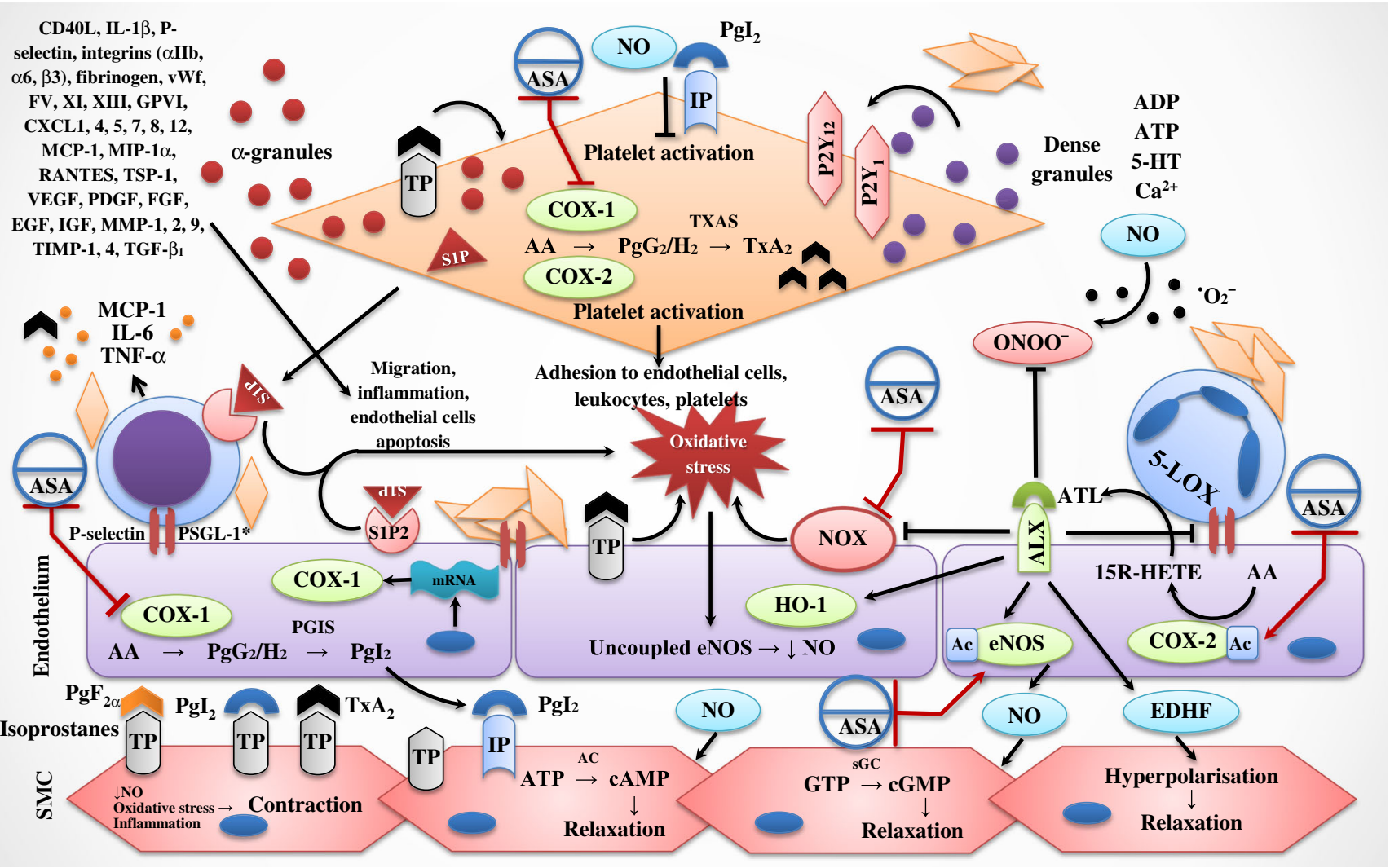

Fig. 1 Influence of aspirin on endothelial function. * Various receptors participate in cellular interactions. 15R-HETE, 15Hydroxyeicosatetraenoic acid; 5-HT, serotonin; 5-LOX, 5lipooxygenase; $A A$, arachidonic acid; $A C$, adenylate cyclase; $I P$, prostacyclin receptor; $A D P$, adenosine diphosphate; $A L X$, ATL receptor; $A S A$, acetyl salicylic acid; $A c$, acetyl group; $A T L$, aspirin-triggered 15-epilipoxin $\mathrm{A}_{4} ; A T P$, adenosine triphosphate; $c A M P$, cyclic adenosine monophosphate; $c G M P$, cyclic guanosine monophosphate; $C O X$, cyclooxygenase; $C X C L 1,4,5,7,8,12$, chemokine (C-X-C motif) ligand $1,4,5,7,8$ and 12, respectively; $E D H F$, endothelium-derived hyperpolarising factor; $E G F$, epidermal growth factor; $e N O S$, endothelial nitric oxide synthase; $F V, X I, X I I I$, coagulation factors V, XI, XIII, respectively; $F G F$, fibroblast growth factor; $G P V I$, collagen receptor; $G T P$, guanosine triphosphate; $H O-1$, heme oxygenase $1 ; I G F$, insulinlike growth factor; $I L-1 \beta$, interleukin- $1 \beta ; I L-6$, interleukin-6; $M C P-1$,

receptors, thus stabilising them; vice versa, continuous signalling via TP receptors leads to downstream generation of more reactive oxygen species (ROS) [25-27]. Angiotensin II, the major effector of the renin-angiotensin system not only promotes hypertension, myocardial and vascular remodelling, but it also contributes to activation of $\mathrm{TxA}_{2}$ synthesis and increased expression of TP receptors either directly or through nicotinamide adenine dinucleotide phosphate oxidase (NOX) activation $[28,29]$.

Endothelial nitric oxide synthase (eNOS) uncoupling (via oxidation of eNOS cofactor tetrahydrobiopterin) and diminished NO bioavailability are other well-recognised consequences of oxidative stress in endothelium (Fig. 1). Essentially, these processes lead to reduction of its vasodilation, anti-aggregatory and anti-inflammatory effects and monocyte chemoattractant protein $1 ; M I P-1 \alpha$, macrophage inflammatory protein $1 \alpha ; M M P-1,2,9$, matrix metalloproteinase 1,2 and 9, respectively; $m R N A$, matrix ribonucleic acid; $N O$, nitric oxide; $N O X$, nicotinamide adenine dinucleotide phosphate-oxidase; $P D G F$, platelet-derived growth factor; $P g G_{2} / \mathrm{H}_{2}$, prostaglandin $\mathrm{G}_{2} / \mathrm{H}_{2} ; \mathrm{PgI}_{2}$, prostacyclin; $P G I S$, prostacyclin synthase; $P S G L-1$, P-selectin glycoprotein ligand 1; $R A N T E S$, regulated on activation, normal T Cell expressed and secreted; $S 1 P$, phingosine-1-phosphate; $S 1 P 2, \mathrm{~S} 1 \mathrm{P}$ receptor 2 ; $s G C$, soluble guanylate cyclase; $S M C$, smooth muscle cell; $T G F-\beta_{1}$, transforming growth factor beta 1; TIMP-1, 4, tissue inhibitor of MMP 1 and 4, respectively; $T N F-\alpha$, tumour necrosis factor $\alpha$; $T P$, thromboxane prostanoid receptor; $T S P-1$, thrombospondin $1 ; T x A_{2}$, thromboxane $\mathrm{A}_{2}$; $T X A S$, thromboxane $\mathrm{A}_{2}$ synthase; $V E G F$, vascular endothelial growth factor; $v W F$, von Willebrand factor

exaggeration of above described changes [27]. Instead of counterbalancing of vasoconstriction, platelet activation and other pathological effects of $\mathrm{TxA}_{2}, \mathrm{NO}$ when exposed to ROS, results in peroxynitrite formation. This was found to upregulate $\mathrm{TxA}_{2}$ synthesis and nitration of PGIS and promote platelet activation [30,31]. Platelet activation is also associated with a release of thrombospondin- 1 from $\alpha$-granules that was shown to diminish NO-dependent vasodilation in arteries via induction of ROS [32].

Thromboxane $\mathrm{A}_{2}$-triggered NOX also upregulates phosphodiesterase type 4 , which leads to hydrolysis of a downstream mediator of prostacyclin, cyclic adenosine monophosphate (cAMP), reducing its favourable vasoprotective and vasodilatory effects [33]. At a background of oxidative stress 8 -isoprostane $\left(\mathrm{PgF}_{2 \alpha}\right)$ is synthesised in 
increased amount and may serve as TP receptor ligand, causing similar to $\mathrm{TxA}_{2}$ downstream effects [34]. Selective blockade of NOX, on the contrary, is associated with decrease in $\mathrm{TxA}_{2}$, and it improves vasodilatory response in arteries [35].

Apart from ROS-mediated decrease in NO, stimulation of TP receptors also inhibits endothelial NO production via direct suppression of eNOS phosphorylation [36]. This relationship appears to be reciprocal, as inhibition of NO production, e.g. with L-NAME $\left(\mathrm{N}^{\mathrm{G}}\right.$-methyl-L-arginine acetate ester), activates aggregation of platelets [37]. Consequently, NO within platelets is involved in regulation of platelet activation and aggregation (Fig. 1). The mechanisms involved are not entirely clear, and they are at least partly mediated by a NOdependent release of calcium from the platelet dense granules. Reduction in NO levels causes accumulation of calcium in platelets cytoplasm. This triggers $\mathrm{TxA}_{2}$ synthesis from the arachidonic acid located within the platelet membrane phospholipids. Interestingly, Banerjee et al. showed that decreased NO synthesis in platelets was a convergent point in platelet activation pathway irrespectively of an activating agent via various platelet receptors (i.e. adenosine diphosphate, collagen, thrombin or epinephrine) [38].

Endothelium-dependent hyperpolarisation, another important mechanism of vasodilation and regulation of the blood flow, is also interfered with $\mathrm{TxA}_{2}$ due to its involvement in modulation of $\mathrm{Ca}^{2+}$-activated potassium channels [39]. Moreover, it impairs signal propagation through gap junctions within endothelial layer and smooth muscle cells that affects endothelium dependent hyperpolarisation and vasodilation (Fig. 1) [39].

In line with NO-dependent mechanisms and endotheliumdependent hyperpolarisation, prostacyclin counteracts the vasocontracting factors, like as $\mathrm{TxA}_{2}$ and other prostanoids, endothelin I, angiotensin II, etc. Prostacyclin can be synthesised both in endothelial cells and vascular smooth muscle cells, and it is the most abundant prostaglandin among other prostanoids. Similarly to $\mathrm{TxA}_{2}$, prostacyclin works locally, and then metabolised to 6-keto-PgF1 $\alpha$. Prostacyclin effects are realised via prostacyclin receptors (IP), which are also have widely distributed in tissues (Fig. 1) [11, 40, 41].

There are also two competing points of view whether COX-1 or COX-2 is the main isotype contributing to prostacyclin synthesis [11, 40, 42, 43]. This question has been extensively discussed, since a decrease in prostacyclin levels has long been considered as the main cause of adverse cardiovascular events associated with COX-2 selective inhibitors [44]. Indeed, selective COX-2 depletion in vascular smooth muscle cells and endothelial cell in mice decreased prostacyclin levels, which was associated with blood pressure elevation and accelerated atherogenesis [45]. However, recent data favour COX-1, as the source of prostacyclin synthesis in vasculature both under basal conditions and stimulation with shear stress or pharmacologically [43, 46, 47].

These data may provide some insights into the mechanisms of hypertension. Simplistically, hypertension occurs when endothelium-dependent vasoconstriction outweighs vasorelaxation, due to either decreased production of endotheliumderived relaxing factors or increased production of endothelium-derived contractile factors, or both [5]. Obviously, pathogenesis of hypertension is complex and this is only one of the multiple pathways involved.

Interplay between mediators, receptors and cellular environment is also complex. This can be illustrated by the prostacyclin effects on vasculature. COX-1 is likely to be the main source of prostacyclin synthesis; however, COX-2 is likely to input towards the prostacyclin pool, particularly in various conditions known to be associated with endothelial dysfunction, e.g. arterial hypertension, atherosclerosis, diabetes mellitus and aging [43, 48, 49]. Also patterns of enzymes and receptors expression may vary, depending on setting.

In terms of signalling via $\mathrm{TxA}_{2}$ receptors and intermediate metabolite in prostanoi synthesis, $\mathrm{PgH}_{2}$ were considered as major drivers of endothelium-dependent contraction, while $\mathrm{NO}$ and prostacyclin as potent relaxing factors. However, prostacyclin was yielded to serve as a contracting agent as well, when binding to TP receptors rather than to IP receptors (Fig. 1) [40, 41]. This appears to happen when IP receptors are getting dysfunctional, e.g. in cardiovascular diseases associated with endothelial dysfunction. Compensatory increase in prostacyclin synthesis in these settings (previously considered as protective mechanism) [50] results in more prostacyclin bound to TP receptors [41, 51]. For example, Liu et al. observed contraction of mice aorta, the effect that was eliminated either at a receptor level (via inhibition of TP receptors) or by reduction of prostacyclin synthesis via COX-1 knockout at a background of low $\mathrm{TxA}_{2}$ synthesised [52].

Reduced NO release further exaggerates the imbalance [53]. Under physiological conditions, when sufficient NO is available, prostacyclin produces IP receptors-mediated vasodilation. In contrast, when NO availability is low, signalling via TP receptors is triggered by prostacyclin [40, 41, 43]. Given that expression of eNOS in hypertension in endothelium is reduced, prostacyclin is prone to trigger signalling via TP receptors [49].

\section{Thromboxane $A_{2}$ Inhibition: Cyclooxygenase-1 Versus Target-Specific Drugs}

Platelet aggregation is part of maintenance of haemostasis and homeostasis. Nonetheless, in cardiovascular diseases, linked to endothelial damage, platelet functioning exceeds physiological range and risk of thrombotic complications increases [54]. In 
clinical practice, aspirin is the most commonly used antiplatelet agent for prevention of adverse events in patients with cardiovascular or cerebrovascular disease [55]. Preventive effect is achieved via inhibition of platelet activation and aggregation due to inhibition of $\mathrm{TxA}_{2}$ synthesis. Apparently, one can also anticipate breaking the vicious cycle of $\mathrm{TxA}_{2}$-mediated platelet activation, oxidative stress, vascular inflammation, eNOS uncoupling and reduced NO bioavailability with $\mathrm{TxA}_{2}$ inhibition. Resulting effects are essentially beneficial for vascular function irrespectively of the nature of disease, e.g. coronary artery disease, hypertension, or arrhythmia.

Indeed, taking into account consequences of activations of TP receptors, their inhibition could be clinically beneficial. Several drugs were developed to avoid side effects associated with COX-1 inhibition, but to retain beneficial effects of TP signalling interruption $[56,57]$. A selective inhibitor of TXAS synthase and TP receptor antagonist (BM-573) was tested in apolipoprotein E knockout mice, a model of atherosclerosis associated with reduced endothelium-derived relaxation and NO bioavailability, enhanced oxidative stress and blood pressure elevation. The treatment led to improvement in all of the above parameters [56]. Reduction in blood pressure and abolished atherosclerosis progression were also observed in other experimental studies of TP antagonists [28, 58, 59].

Terutroban (S18886) is perhaps the best known TP receptor antagonist. In animal studies, terutroban showed ability to reduce NOX upregulation and ROS production [60], improve endothelial function [36] and attenuate renal damage in hypertension [61]. In spontaneously hypertensive stroke-prone rats, the use of terutroban prevented cell proliferation in the vessel media, abolished accumulation of collagen and fibronectin in the vascular wall and inhibited expression of heat shock protein-47, MCP-1 and transforming growth factor $1 \beta[62,63]$.

Although in some experiments effects of terutroban on inflammation and endothelial function even outweighed effects of aspirin [63], positive effects of TP receptors blockade obtained in animal models did not translate into better outcomes in humans [64]. In the PERFORM trial (Prevention of cerebrovascular and cardiovascular Events of ischaemic origin with teRutroban in patients with a history oF ischaemic strOke or tRansient ischaeMic attack), there was a similar rate of primary end-point of fatal or non-fatal ischaemic stroke, fatal or non-fatal myocardial infarction, or other vascular death observed in terutroban and aspirin groups (11 vs. $11 \%$, hazard ratio (HR) 1.02, $95 \%$ confidence interval (CI) 0.94-1.12) and increased risk of minor bleeding in terutroban arm (12 vs. $11 \%$, HR 1.11, $95 \%$ CI 1.02-1.21) [64]. The trial was stopped prematurely. There was also no difference in carotid atherosclerosis progression, assessed by carotid intima-media thickness measurements and carotid plaques between the two treatment groups [65]. Nonetheless, despite the lack of clinical success so far, selective inhibition of $\mathrm{TxA}_{2}$, either by synthesis or TP receptors or both, remains one of attractive pharmacological targets in cardiology $[56,57]$.

\section{Aspirin and Endothelial Function: Beyond Thromboxane A Inhibition}

What makes the difference between aspirin and selective $\mathrm{TxA}_{2}$ inhibition given controversies between animal and bedside data? One explanation is that dual inhibition, TXAS and TP receptors is required because the latter can be activated by other substances, e.g. isoprostanes [56]. Obviously, the more pathways of platelets activation are blocked, the higher effectiveness of treatment is expected in relation to both clinical outcomes and endothelial function [66, 67]. Also, aspirin has a plethora of favourable vascular effects in addition to modulation of the COX-1-dependent $\mathrm{TxA}_{2}$ synthesis and platelet activation, which will be discussed below. Noteworthy, decrease in prostacyclin synthesis in endothelium, due to COX-1 inhibition, was thought to be an unfavourable effect of aspirin, now in light of emerging role of prostacyclin in TP receptor signalling is considered to be advantageous [48]. It was also discovered that IP and TP receptors were capable of formation of heterodimeric receptor complex. Within such complex biological downstream effects of TP receptors can shift towards those realised via IP receptors stimulation [68].

\section{Endothelial Nitric Oxide Synthase Acetylation}

Aspirin was found to acetylate lysine of eNOS, which evokes activation of its enzymatic activity, i.e. NO synthesis, release and bioavailability of NO not only in endothelial cells, but also in platelets (Fig. 1). Moreover, this effect appeared to be independent of COX-1 inhibition and $\mathrm{TxA}_{2}$ production [69-72]. Obviously, in platelets pre-treated with aspirin, $\mathrm{TxA}_{2}$ level is reduced; thus, their activation is prevented by modulation of both pathways, and downstream decrease in platelet-mediated inflammation in vascular wall can be expected $[38,73]$.

Two small clinical trials assessed the effect of various doses of aspirin, ranging 81 to $1300 \mathrm{mg}$, on NO production in patients with metabolic syndrome and coronary artery disease. NO production was indirectly assessed based on levels of heme-oxygenase-1 (HO-1), which is known to be upregulated with increased NO production, and asymmetrical dimethylarginine (ADMA), that serves as eNOS inhibitor. These biomarkers were measured at baseline and after 12 weeks of the treatment. In both primary and secondary prevention cohorts, aspirin increase in HO-1 and decrease in ADMA indicate its ability to increase $\mathrm{NO}$ production $[74,75]$. 


\section{Aspirin-Triggered Lipoxins and Resolvins}

Lipoxins are a type of lipid mediators generated from arachidonic acid. Following aspirin intake, COX-2 is acetylated that switches its enzymatic activity from a prostaglandin endoperoxide synthase to a lipoxygenase pathway (Fig. 1). First, intermediate 15(R)-hydroxyeicosatetraenoic acid is synthesised, then it is converted to ATL by 5-, 12-, or 15-lipoxygenases in various cell types (e.g. endothelial cells, platelets and leukocytes) to 15R-epimers of intrinsic lipoxin A4 and B4, defined as 15-epi-lipoxins or aspirin-triggered lipoxins (ATL) [76, 77].

Aspirin-triggered lipoxins are considered to be more potent than intrinsic lipoxins with effects mediated via appropriate receptor lipoxin A4 receptor (ALX) / formyl peptide receptor (FPR2) with high affinity to it [76, 77]. Aspirin-triggered lipoxins are capable of reduction of NOX-mediated endothelial production of ROS via suppression of redox-sensitive activation of the transcriptional factor nuclear factor-kappa B, induced by either angiotensin II, tumour necrosis factor- $\alpha$, or thrombin [78]. Aspirin-triggered lipoxins also block plateletderived growth factor-stimulated proliferation and migration of smooth muscle cells in vasculature [79]. ATL were shown to reduce adhesion of human leukocytes to endothelial cells, reducing inflammation within the vascular wall $[80,81]$. Given the role platelets play in regulation of leukocytes adhesion to vascular endothelium, lipoxins released by plateletleukocyte aggregates control leukocyte activation and adhesion and reduce damage to the vascular wall [82]. Noteworthy, ATL levels were found to be reduced in patients with atherosclerotic lesions, particularly in patients with advanced atherosclerosis [79].

Resolvins (resolution phase interaction products) represent another group of substances with potent anti-inflammatory properties. Resolvins are synthesised from docosohexaenoic and eicosopentaenoic omega-3 polyunsaturated fatty acids (PUFA); hence, PUFA supplementation was found to restore resolvins level if decreased in cardiovascular disease [83].

For example, resolvin E1 (RvE1) is generated by the transformation of 18R-hydro (peroxy)-eicosapentaenoic acid, which in turn is synthesised by the aspirin-acetylated COX-2 in endothelium. Resolvin E1 inhibits transmigration and infiltration of polymorphonuclear leukocytes in vascular wall as well as formation of platelet aggregates [84]. Significant decrease of expression of pro-inflammatory cytokines and adhesion molecules, increase in RvE1 level and, interestingly, decrease in blood pressure were observed in mice treated with fish oil (as source of PUFA) and aspirin [85].

\section{Sphingosine-1 Phosphate}

Lysosphingolipid sphingosine-1 phosphate (S1P) is another mediator released from platelets in large quantities upon activation, during thrombus formation and inflammation. Given that the $\mathrm{S} 1 \mathrm{P}$ release is promoted by $\mathrm{TxA}_{2}$, aspirin indirectly inhibits S1P signalling (Fig. 1). Sphingosine-1 phosphate is produced via two isoforms of sphingosine kinase (SphK), of which SphK2 is predominant in platelets, and then binds to S1P receptors on endothelial cells and smooth muscle cells [86].

Circulating S1P may confer protective signalling for vasculature by taking part in maintenance of endothelial layer integrity, reduction in expression of adhesion molecules in endothelium and inhibition of leukocyte adhesion to the endothelium, and increase NO production (mostly via S1P1 receptor). On the contrary, opposing effects are triggered by high levels of S1P released locally from the activated platelets (via S1P2 receptor) [87].

\section{Clinical Implications of Aspirin Use in Hypertension}

\section{Impact of Aspirin on Vasculature and Blood Pressure: Bedside Data}

Few studies addressed impact of aspirin on vascular function and blood pressure in patients with arterial hypertension. Moreover, the studies were generally small and heterogeneous in term of the studies population, concomitant drugs use, aspirin dose, duration of treatment and generally had small numbers. For example, Pietri et al. assessed effect of $160 \mathrm{mg}$ of aspirin administered for 2 weeks, on blood pressure and parameters of arterial stiffness in a small group, of untreated patients with mild hypertension. They observed $0.5 \mathrm{~m} / \mathrm{s}$ reduction in pulse wave velocity in the aspirin arm of the study (which they reasonably attributed to endothelial function and vascular tone), and there were no changes found in placebo arm. There was no significant decrease in blood pressure as well [88]. Another study, with similar aspirin dosing and duration of treatment, showed improvement in flow-mediated dilation and decrease in C-reactive protein and intercellular adhesion molecules level with aspirin. However, due to the study design, it was impossible to reliably separate effects of aspirin from effects of concomitant treatments [89]. In another study, aspirin therapy resulted in improvement of flowmediated dilation and blood pressure reduction, when combined with statins, while no significant dynamics was observed on aspirin monotherapy [90].

The impact of aspirin on blood pressure was found to depend on the time of administration and also to differ in males and females. Hermida et al. performed a series of studies that addressed time-dependent effect of low-dose aspirin $(100 \mathrm{mg})$ administration. Interestingly, a 3-month course of treatment resulted in a minor but significant reduction of ambulatory blood pressure when patients received aspirin at bedtime rather than at awakening, both in mild hypertension and prehypertension states [91-94]. The effect was consistent across 
patients subgroups, but particularly pronounced in females and non-dippers [93, 94].

Overall, robust clinical data on effects of aspirin on vascular function and blood pressure control are scarce, which prevents reliable conclusion on clinical significance of these effects.

\section{Prevention of Cardiovascular and Cerebrovascular Events}

Despite high blood pressure values being the major cause of vascular complications per se, duration of hypertension, particularly when poorly controlled, is associated with 'silent' endothelial damage that in turn hastens atherosclerosis progression $[1,4]$. Thus, patients with no clinically apparent coronary artery disease may have their first manifestation of $\mathrm{CAD}$ as acute one, e.g. acute coronary syndrome [54].

Despite multiple effects of aspirin that in theory can reduce blood pressure, it is not clinically used for blood pressure lowering. However, given that in management of patients with arterial hypertension, prevention of adverse cardiovascular events is crucial, many hypertensive patients use the agent. Aspirin has a large body of evidence favouring its use for the secondary prevention, but use of aspirin for primary prevention remains controversial. Recent European guidelines on cardiovascular disease prevention did not support prophylactic use of aspirin in individuals without established cardiovascular disease because the risk of major bleeding outweighs the minor decrease in rate of major adverse cardiac events [55]. However, European guidelines for the management of arterial hypertension suggested consideration of aspirin use for primary prevention in patient with high cardiovascular risk or reduced kidney function based on more balanced risk-benefit profile in these categories of patients [95].

The US Preventive Services Task Force has also recently updated recommendations on the use of aspirin for the primary prevention of cardiovascular disease and colorectal cancer. Low-dose aspirin is now supported in men and women aged 50 to 59 years who have a predicted risk for myocardial infarction or stroke of at least $10 \%$ over 10 years, with no elevated bleeding risk, and willing to take aspirin within 10 years or longer. In patients aged 60 to 69 years, a decision has to be made on an individual basis. Other age groups were omitted in the document because of the lack of evidence [96].

Broadly, similar principles were incorporated in the recommendations for antiplatelet treatment for primary prevention of cardiovascular disease in the UK. Age over 50 years with a high cardiovascular risk, defined as 10 years risk of greater than $20 \%$, or reduced renal function (e.g. estimated glomerular filtration rate less than $45 \mathrm{~mL} / \mathrm{min} / 1.73 \mathrm{~m}^{2}$ ) are the clinical scenarios, when aspirin treatment in patients with hypertension can be recommended [97].

There is also controversy in relation to aspirin use in primary prevention settings in patients with diabetes, which is closely linked to other cardiovascular risk factors and cardiovascular morbidity, including hypertension and coronary artery disease. Diabetes is known to be associated with persistent $\mathrm{TxA}_{2}$-dependent platelet activation [98]. In diabetic patients, aspirin use showed a significant $10 \%$ reduction of risk of major adverse cardiovascular events, with no effect on myocardial infarction, stroke, cardiovascular or all-cause mortality, and a trend towards higher rate of gastrointestinal bleeds [99].

Despite relation between hazards and benefits of aspirin for primary prevention remained broadly stable with adding new clinical trials to meta-analyses (Table 1), update for evidence is still needed at least because of the following reasons. Widespread use of statins for primary prevention needs to be accounted for as well improving control of cardiovascular risk factors, e.g. hypertension itself, smoking and obesity. These factors can modulate the overall net benefits of aspirin for primary prevention, and they need to be accounted for future analyses.

\section{Ongoing Trials}

There are several on-going trials on the utility of aspirin in primary prevention settings. The ARRIVE (Aspirin to Reduce Risk of Initial Vascular Events) study aims to evaluate the efficacy and tolerability of $100 \mathrm{mg}$ enteric-coated aspirin compared to placebo in patients with no history of established cardiovascular disease and moderate risk of major coronary heart disease events for the prevention of cardiovascular disease events, including myocardial infarction, unstable angina, stroke or transient ischaemic attack, as well as cardiovascular death [107]. In the ASPREE (Aspirin in Reducing Events in the Elderly) trial effects of $100 \mathrm{mg}$ enteric-coated aspirin on the composite primary endpoint, defined as 'disability-free life', including onset of dementia, all-cause mortality, or persistent disability in at least one of the Katz Activities are assessed in individuals free of dementia, disability and cardiovascular disease [108].

There are also two ongoing trials, addressing aspirin for primary prevention in diabetic patients, who are known to be particularly prone to develop atherosclerosis and coronary artery disease, but based on current guidelines should not take aspirin for primary prevention [55]. The ACCEPT-D (Aspirin and Simvastatin Combination for Cardiovascular Events Prevention Trial in Diabetes) assesses efficacy of aspirin, added to simvastatin in patients with either type I or type II diabetes mellitus on development of the primary combined end-point of cardiovascular death, non-fatal myocardial infarction, non-fatal stroke and hospital admission for cardiovascular causes, including acute coronary syndrome, transient ischemic attack, not planned revascularization procedures, peripheral vascular disease [109]. In the ASCEND (A Study of Cardiovascular Events iN Diabetes), patients are randomised to aspirin and/or omega-3 fatty acid for the primary prevention 
of cardiovascular events [110]. Finally, the TIPS-3 (International Polycap Study 3) trial will assess effect of combination of enteric-coated aspirin and cholecalciferol versus placebo on the composite end point of major cardiovascular disease (cardiac death, non-fatal stroke, non-fatal myocardial infarction), plus heart failure, resuscitated cardiac arrest, or revascularization with evidence of ischemia; aspirin versus placebo on composite of cardiovascular events (cardiac death, myocardial infarction or stroke) and cancer as well as risk of fractures against a cholecalciferol therapy [111]. These new studies would hopefully optimise utilisation of aspirin for primary prevention and identify patients groups who are likely to benefit from such treatment.

\section{High On-treatment Platelet Reactivity}

High-on-treatment platelet reactivity (or less appropriately termed as aspirin resistance) refers to failure of aspirin to prevent cardiovascular events [112]. It is less related to use of aspirin in hypertension because of limited indications in this group of patients, but representing an important phenomenon of aspirin, platelets and endothelial dysfunction interplay. Such patients were found to have approximately four time higher risk of cardiovascular events, compared to patients with low residual platelet reactivity $[113,114]$. It is often explained by insufficient inhibition of $\mathrm{TxA}_{2}$ synthesis in platelets; however, precise mechanisms have not been fully elucidated, yet [115].

First, platelets are activated via multiple pathways and receptors, among which aspirin targets only one. Multiple studies showed substantial decrease in $\mathrm{TxB}_{2}$ level, reflecting diminished $\mathrm{TxA}_{2}$ synthesis; however, applying COX-1 functional testing, as a reliable measure for residual platelet reactivity and prognostication of cardiovascular outcomes, remained controversial [17, 112, 116-119]. Second, non-platelet sources of $\mathrm{TxA}_{2}$ generation should be considered, specifically, endothelium and monocytes/macrophages $[8,10,120]$. Therefore, usual once a day dosing regimen may be less effective to assure continuous inhibition of $\mathrm{TxA}_{2}$ synthesis [121, 122]. Third, environment in vasculature seems to play important role, e.g. oxidative stress, inflammation, NO synthesis as well as patient characteristics which are causative of the former like as smoking, obesity and diabetes mellitus [9•, 123, 124•, 125•]. For example, brachial flow-mediated dilation was found to be inversely associated with platelet adhesion and aggregation [124•]. Also, immature reticulated platelets were found to be less suppressed by antiplatelet drugs [126].

\section{Conclusions}

Aspirin has been introduced into clinical practice more than a century ago, and its use is supported by large body of evidence, e.g. for secondary prevention of cardiovascular events. 
Despite this, it is increasingly acknowledged that the multitude of actions of aspirin is not fully elucidated yet. Ongoing trials may spread current use of aspirin to new areas, which are now considered largely controversial. Notwithstanding pleiotropic effects of aspirin on endothelial function, it is unlikely that we will start using aspirin as an antihypertensive agent; however, this may bring additional clinical benefits in selected patients with hypertension, for primary prevention of adverse cardiovascular events.

\section{Compliance with Ethical Standards}

Conflict of Interest Drs. Dzeshka, Shantsila, and Lip declare no conflicts of interest relevant to this manuscript.

Human and Animal Rights and Informed Consent This article does not contain any studies with human or animal subjects performed by any of the authors.

Open Access This article is distributed under the terms of the Creative Commons Attribution 4.0 International License (http:// creativecommons.org/licenses/by/4.0/), which permits unrestricted use, distribution, and reproduction in any medium, provided you give appropriate credit to the original author(s) and the source, provide a link to the Creative Commons license, and indicate if changes were made.

\section{References}

Papers of particular interest, published recently, have been highlighted as:

- Of importance

1. Cahill PA, Redmond EM. Vascular endothelium — gatekeeper of vessel health. Atherosclerosis. 2016;248:97-109.

2. Deshko MS, Snezhitsky VA, Dolgoshey TS, Madekina GA, Stempen TP. Flow-mediated dilation in patients with paroxysmal atrial fibrillation: initial evaluation, treatment results, pathophysiological correlates. Europace : Eur, Arrhythmias, Cardiac Electrophysiol: J Working Groups Cardiac Pacing, Arrhythmias, Cardiac Cell Electrophysiol Eur Soc Cardiol. 2011;13(suppl 3).

3. Kornej J, Apostolakis S, Bollmann A, Lip GY. The emerging role of biomarkers in atrial fibrillation. Can J Cardiol. 2013;29(10): 1181-93.

4. Lehoux S, Jones EA. Shear stress, arterial identity and atherosclerosis. Thromb Haemost. 2016;115(3):467-73.

5. Brandes RP. Endothelial dysfunction and hypertension. Hypertension. 2014;64(5):924-8.

6. De Miguel C, Rudemiller NP, Abais JM, Mattson DL. Inflammation and hypertension: new understandings and potential therapeutic targets. Curr Hypertens Rep. 2014;17(1):1-10.

7. Schrottmaier WC, Kral JB, Badrnya S, Assinger A. Aspirin and P2Y12 inhibitors in platelet-mediated activation of neutrophils and monocytes. Thromb Haemost. 2015;114(9):478-89.

8. Muller KA, Chatterjee M, Rath D, Geisler T. Platelets, inflammation and anti-inflammatory effects of antiplatelet drugs in ACS and CAD. Thromb Haemost. 2015;114(3):498-518.
9. Thomas MR, Storey RF. The role of platelets in inflammation. Thromb Haemost. 2015;114(9):449-58. Comprehensive review of the role of platelets in inflammation.

10. Hohlfeld T, Schrör K. Antiinflammatory effects of aspirin in ACS: relevant to its cardiocoronary actions? Thromb Haemost. 2015;114(9):469-77.

11. Feletou M, Huang Y, Vanhoutte PM. Endothelium-mediated control of vascular tone: $\mathrm{COX}-1$ and $\mathrm{COX}-2$ products. $\mathrm{Br} \mathrm{J}$ Pharmacol. 2011;164(3):894-912.

12. Alfonso L, Ai G, Spitale RC, Bhat GJ. Molecular targets of aspirin and cancer prevention. Br J Cancer. 2014;111(1):61-7.

13. Dai SX, Li WX, Li GH, Huang JF. Proteome-wide prediction of targets for aspirin: new insight into the molecular mechanism of aspirin. Peer J. 2016;4:e1791. An analysis showing multiple targets for aspirin.

14. Serebruany VL, Cherepanov V, Cabrera-Fuentes HA, Kim MH. Solid cancers after antiplatelet therapy: confirmations, controversies, and challenges. Thromb Haemost. 2015;114(12):1104-12.

15. Nagelschmitz J, Blunck M, Kraetzschmar J, Ludwig M, Wensing G, Hohlfeld T. Pharmacokinetics and pharmacodynamics of acetylsalicylic acid after intravenous and oral administration to healthy volunteers. Clin Pharmacol: Adv Appl. 2014;6:51-9.

16. Smyth EM. Thromboxane and the thromboxane receptor in cardiovascular disease. Clin Lipidol. 2010;5(2):209-19.

17. Petrucci G, Rizzi A, Cavalca V, Habib A, Pitocco D, Veglia F, et al. Patient-independent variables affecting the assessment of aspirin responsiveness by serum thromboxane measurement. Thrombosis Haemostasis. 2016(2016-07-21 00:00:00).

18. Gleim S, Stitham J, Tang WH, Li H, Douville K, Chelikani P, et al. Human thromboxane A2 receptor genetic variants: in silico, in vitro and "in platelet" analysis. PLoS ONE. 2013;8(6), e67314.

19. Katugampola SD, Davenport AP. Thromboxane receptor density is increased in human cardiovascular disease with evidence for inhibition at therapeutic concentrations by the AT(1) receptor antagonist losartan. Br J Pharmacol. 2001;134(7):1385-92.

20. Blair P, Flaumenhaft R. Platelet $\alpha$-granules: basic biology and clinical correlates. Blood Rev. 2009;23(4):177-89.

21. Koenen RR. The prowess of platelets in immunity and inflammation. Thrombosis Haemostasis. 2016(2016-07-07 00:00:00).

22. Soon ASC, Chua JW, Becker DL. Connexins in endothelial barrier function - novel therapeutic targets countering vascular hyperpermeability. Thrombosis Haemostasis. 2016(2016-08-04 00:00:00).

23. Pierini D, Bryan NS. Nitric oxide availability as a marker of oxidative stress. Methods Mol Biol (Clifton, NJ). 2015;1208:63-71.

24. Higashi Y, Maruhashi T, Noma K, Kihara Y. Oxidative stress and endothelial dysfunction: clinical evidence and therapeutic implications. Trends Cardiovasc Med. 2014;24(4):165-9.

25. Ball SK, Field MC, Tippins JR. Regulation of thromboxane receptor signaling at multiple levels by oxidative stress-induced stabilization, relocation and enhanced responsiveness. PLoS ONE. 2010;5(9), e12798.

26. Muzaffar S, Shukla N, Massey Y, Angelini GD, Jeremy JY. NADPH oxidase 1 mediates upregulation of thromboxane A2 synthase in human vascular smooth muscle cells: inhibition with iloprost. Eur J Pharmacol. 2011;658(2-3):187-92.

27. Zhang M, Song P, Xu J, Zou MH. Activation of NAD(P)H oxidases by thromboxane A2 receptor uncouples endothelial nitric oxide synthase. Arterioscler Thromb Vasc Biol. 2011;31(1):12532.

28. Francois H, Athirakul K, Mao L, Rockman H, Coffman TM. Role for thromboxane receptors in angiotensin-II-induced hypertension. Hypertension. 2004;43(2):364-9.

29. Sparks MA, Makhanova NA, Griffiths RC, Snouwaert JN, Koller $\mathrm{BH}$, Coffman TM. Thromboxane receptors in smooth muscle 
promote hypertension, vascular remodeling, and sudden death. Hypertension. 2013;61(1):166-73.

30. Schildknecht S, van der Loo B, Weber K, Tiefenthaler K, Daiber A, Bachschmid MM. Endogenous peroxynitrite modulates PGHS-1-dependent thromboxane A2 formation and aggregation in human platelets. Free Radic Biol Med. 2008;45(4):512-20.

31. Zou MH. Peroxynitrite and protein tyrosine nitration of prostacyclin synthase. Prostaglandins Lipid Mediators. 2007;82(1-4):119 27.

32. Nevitt C, McKenzie G, Christian K, Austin J, Hencke S, Hoying J, et al. Physiological levels of thrombospondin-1 decrease NOdependent vasodilation in coronary microvessels from aged rats. Am J Physiol Heart Circ Physiol. 2016;310(11):H1842-H50.

33. Muzaffar S, Jeremy JY, Angelini GD, Shukla N. NADPH oxidase 4 mediates upregulation of type 4 phosphodiesterases in human endothelial cells. J Cell Physiol. 2012;227(5):1941-50.

34. Lassegue B, San Martin A, Griendling KK. Biochemistry, physiology, and pathophysiology of NADPH oxidases in the cardiovascular system. Circ Res. 2012;110(10):1364-90.

35. Gamez-Mendez AM, Vargas-Robles H, Rios A, Escalante B. Oxidative stress-dependent coronary endothelial dysfunction in obese mice. PLoS ONE. 2015;10(9), e0138609.

36. Liu CQ, Leung FP, Wong SL, Wong WT, Lau CW, Lu L, et al. Thromboxane prostanoid receptor activation impairs endothelial nitric oxide-dependent vasorelaxations: the role of Rho kinase. Biochem Pharmacol. 2009;78(4):374-81.

37. Banerjee D, Mazumder S, Sinha AK. The role of inhibition of nitric oxide synthesis in the aggregation of platelets due to the stimulated production of thromboxane A2. Blood Coagul Fibrinolysis: Int J Haemostasis Thrombosis. 2014;25(6):585-91.

38. Banerjee D, Mazumder S, Kumar Sinha A. Involvement of nitric oxide on calcium mobilization and arachidonic acid pathway activation during platelet aggregation with different aggregating agonists. Int J Biomed Sci: IJBS. 2016;12(1):25-35.

39. Ellinsworth DC, Shukla N, Fleming I, Jeremy JY. Interactions between thromboxane A(2), thromboxane/prostaglandin (TP) receptors, and endothelium-derived hyperpolarization. Cardiovasc Res. 2014;102(1):9-16.

40. Vanhoutte PM. Endothelium-dependent contractions in hypertension: when prostacyclin becomes ugly. Hypertension. 2011;57(3): 526-31.

41. Luo W, Liu B, Zhou Y. The endothelial cyclooxygenase pathway: insights from mouse arteries. Eur J Pharmacol. 2016;780:148-58.

42. Kirkby NS, Lundberg MH, Harrington LS, Leadbeater PD, Milne GL, Potter CM, et al. Cyclooxygenase-1, not cyclooxygenase-2, is responsible for physiological production of prostacyclin in the cardiovascular system. Proc Natl Acad Sci U S A. 2012;109(43):17597-602.

43. Zhou Y, Luo W, Zhang Y, Li H, Huang D, Liu B. Cyclooxygenase-1 or -2-mediated metabolism of arachidonic acid in endothelium-dependent contraction of mouse arteries. Exp Physiol. 2013;98(7):1225-34.

44. Patrono C. Cardiovascular effects of nonsteroidal antiinflammatory drugs. Curr Cardiol Rep. 2016;18(3):1-8.

45. Tang SY, Monslow J, Todd L, Lawson J, Pure E, FitzGerald GA. Cyclooxygenase-2 in endothelial and vascular smooth muscle cells restrains atherogenesis in hyperlipidemic mice. Circulation. 2014;129(17):1761-9.

46. Kirkby NS, Zaiss AK, Urquhart P, Jiao J, Austin PJ, Al-Yamani $\mathrm{M}$, et al. LC-MS/MS confirms that COX-1 drives vascular prostacyclin whilst gene expression pattern reveals non-vascular sites of COX-2 expression. PLoS ONE. 2013;8(7), e69524.

47. Liu B, Li Z, Zhang Y, Luo W, Zhang J, Li H, et al. Vasomotor reaction to cyclooxygenase-1-mediated prostacyclin synthesis in carotid arteries from two-kidney-one-clip hypertensive mice. PLoS ONE. 2015;10(8), e0136738.
48. Li S, Liu B, Luo W, Zhang Y, Li H, Huang D, et al. Role of cyclooxygenase- 1 and -2 in endothelium-dependent contraction of atherosclerotic mouse abdominal aortas. Clin Exp Pharmacol Physiol. 2016;43(1):67-74.

49. Tang EH, Vanhoutte PM. Gene expression changes of prostanoid synthases in endothelial cells and prostanoid receptors in vascular smooth muscle cells caused by aging and hypertension. Physiol Genomics. 2008;32(3):409-18.

50. Pratico D, Tillmann C, Zhang ZB, Li H, FitzGerald GA. Acceleration of atherogenesis by COX-1-dependent prostanoid formation in low density lipoprotein receptor knockout mice. Proc Natl Acad Sci U S A. 2001;98(6):3358-63.

51. Feletou M, Verbeuren TJ, Vanhoutte PM. Endothelium-dependent contractions in SHR: a tale of prostanoid TP and IP receptors. Br J Pharmacol. 2009;156(4):563-74.

52. Liu B, Luo W, Zhang Y, Li H, Zhu N, Huang D, et al. Involvement of cyclo-oxygenase-1-mediated prostacyclin synthesis in the vasoconstrictor activity evoked by ACh in mouse arteries. Exp Physiol. 2012;97(2):277-89.

53. Liu D, Liu B, Luo W, Li H, Zhang Y, Zhou Y. A vasoconstrictor response to COX-1-mediated prostacyclin synthesis in young rat renal arteries that increases in prehypertensive conditions. Am J Physiol Heart Circ Physiol. 2015;309(5):H804-11.

54. White SJ, Newby AC, Johnson TW. Endothelial erosion of plaques as a substrate for coronary thrombosis. Thromb Haemost. 2016;115(3):509-19.

55. Piepoli MF, Hoes AW, Agewall S, Albus C, Brotons C, Catapano AL, et al. 2016 European Guidelines on cardiovascular disease prevention in clinical practice. Eur Heart J. 2016.

56. Romero M, Leon-Gomez E, Lobysheva I, Rath G, Dogne JM, Feron O, et al. Effects of BM-573 on endothelial dependent relaxation and increased blood pressure at early stages of atherosclerosis. PLoS ONE. 2016;11(3), e0152579.

57. Huang SW, Kuo HL, Hsu MT, Tseng YJ, Lin SW, Kuo SC, et al. A novel thromboxane receptor antagonist, nstpbp5185, inhibits platelet aggregation and thrombus formation in animal models. Thrombosis Haemostasis. 2016;116(2).

58. Francois H, Makhanova N, Ruiz P, Ellison J, Mao L, Rockman HA, et al. A role for the thromboxane receptor in L-NAME hypertension. Am J Physiol Renal Physiol. 2008;295(4):F1096-102.

59. Cayatte AJ, Du Y, Oliver-Krasinski J, Lavielle G, Verbeuren TJ, Cohen RA. The thromboxane receptor antagonist S18886 but not aspirin inhibits atherogenesis in apo E-deficient mice: evidence that eicosanoids other than thromboxane contribute to atherosclerosis. Arterioscler Thromb Vasc Biol. 2000;20(7):1724-8.

60. Del Turco S, Basta G, Lazzerini G, Chancharme L, Lerond L, De Caterina R. Involvement of the TP receptor in TNF-alpha-induced endothelial tissue factor expression. Vasc Pharmacol. 2014;62(2): 49-56.

61. Sebekova K, Ramuscak A, Boor P, Heidland A, Amann K. The selective TP receptor antagonist, S18886 (terutroban), attenuates renal damage in the double transgenic rat model of hypertension. Am J Nephrol. 2008;28(1):47-53.

62. Gelosa P, Sevin G, Pignieri A, Budelli S, Castiglioni L, BlancGuillemaud V, et al. Terutroban, a thromboxane/prostaglandin endoperoxide receptor antagonist, prevents hypertensive vascular hypertrophy and fibrosis. Am J Physiol Heart Circ Physiol. 2011;300(3):H762-8.

63. Gelosa P, Ballerio R, Banfi C, Nobili E, Gianella A, Pignieri A, et al. Terutroban, a thromboxane/prostaglandin endoperoxide receptor antagonist, increases survival in stroke-prone rats by preventing systemic inflammation and endothelial dysfunction: comparison with aspirin and rosuvastatin. J Pharmacol Exp Ther. 2010;334(1):199-205.

64. Bousser MG, Amarenco P, Chamorro A, Fisher M, Ford I, Fox $\mathrm{KM}$, et al. Terutroban versus aspirin in patients with cerebral 
ischaemic events (PERFORM): a randomised, double-blind, parallel-group trial. Lancet (London, England). 2011;377(9782): 2013-22.

65. Bots ML, Ford I, Lloyd SM, Laurent S, Touboul PJ, Hennerici MG. Thromboxane prostaglandin receptor antagonist and carotid atherosclerosis progression in patients with cerebrovascular disease of ischemic origin: a randomized controlled trial. Stroke; J Cerebral Circ. 2014;45(8):2348-53.

66. Chan MV, Knowles RBM, Lundberg MH, Tucker AT, Mohamed NA, Kirkby NS, et al. P2Y12 receptor blockade synergizes strongly with nitric oxide and prostacyclin to inhibit platelet activation. Br J Clin Pharmacol. 2016;81(4):621-33.

67. Thomas MR, Storey RF. Effect of P2Y12 inhibitors on inflammation and immunity. Thromb Haemost. 2015;114(9):490-7.

68. Frey AJ, Ibrahim S, Gleim S, Hwa J, Smyth EM. Biased suppression of TP homodimerization and signaling through disruption of a TM GxxxGxxxL helical interaction motif. J Lipid Res. 2013;54(6):1678-90.

69. Heiss EH, Dirsch VM. Regulation of eNOS enzyme activity by posttranslational modification. Curr Pharm Des. 2014;20(22): 3503-13.

70. Jung SB, Kim CS, Naqvi A, Yamamori T, Mattagajasingh I, Hoffman TA, et al. Histone deacetylase 3 antagonizes aspirinstimulated endothelial nitric oxide production by reversing aspirin-induced lysine acetylation of endothelial nitric oxide synthase. Circ Res. 2010;107(7):877-87.

71. Kabirian F, Amoabediny G, Haghighipour N, Salehi-Nik N, Zandieh-Doulabi B. Nitric oxide secretion by endothelial cells in response to fluid shear stress, aspirin, and temperature. J Biomed Mater Res A. 2015;103(3):1231-7.

72. Ghosh R, Bank S, Maji UK, Bhattacharya R, Guha S, Khan NN, et al. The effect of acetyl salicylic acid induced nitric oxide synthesis in the normalization of hypertension through the stimulation of renal cortexin synthesis and by the inhibition of dermcidin isoform 2, a hypertensive protein production. Int J Biomed Sci: IJBS. 2014;10(3):158-66.

73. Karmohapatra SK, Chakraborty K, Kahn NN, Sinha AK. The role of nitric oxide in aspirin induced thrombolysis in vitro and the purification of aspirin activated nitric oxide synthase from human blood platelets. Am J Hematol. 2007;82(11):986-95.

74. Hennekens CH, Schneider WR, Pokov A, Hetzel S, Demets D, Serebruany $\mathrm{V}$, et al. A randomized trial of aspirin at clinically relevant doses and nitric oxide formation in humans. J Cardiovasc Pharmacol Ther. 2010;15(4):344-8.

75. Hetzel S, DeMets D, Schneider R, Borzak S, Schneider W, Serebruany V, et al. Aspirin increases nitric oxide formation in chronic stable coronary disease. J Cardiovasc Pharmacol Ther. 2013;18(3):217-21.

76. Schror K, Rauch BH. Aspirin and lipid mediators in the cardiovascular system. Prostaglandins Lipid Mediators. 2015;121(Pt A):17-23.

77. Romano M, Cianci E, Simiele F, Recchiuti A. Lipoxins and aspirin-triggered lipoxins in resolution of inflammation. Eur J Pharmacol. 2015;760:49-63.

78. Nascimento-Silva V, Arruda MA, Barja-Fidalgo C, Fierro IM. Aspirin-triggered lipoxin A4 blocks reactive oxygen species generation in endothelial cells: a novel antioxidative mechanism. Thromb Haemost. 2007;97(1):88-98.

79. Ho KJ, Spite M, Owens CD, Lancero H, Kroemer AH, Pande R, et al. Aspirin-triggered lipoxin and resolvin E1 modulate vascular smooth muscle phenotype and correlate with peripheral atherosclerosis. Am J Pathol. 2010;177(4):2116-23.

80. Vital SA, Becker F, Holloway PM, Russell J, Perretti M, Granger DN, et al. Formyl-peptide receptor 2/3/Lipoxin a4 receptor regulates neutrophil-platelet aggregation and attenuates cerebral inflammation: impact for therapy in cardiovascular disease. Circulation. 2016;133(22):2169-79.
81. Gil-Villa AM, Norling LV, Serhan CN, Cordero D, Rojas M, Cadavid A. Aspirin triggered-lipoxin A4 reduces the adhesion of human polymorphonuclear neutrophils to endothelial cells initiated by preeclamptic plasma. Prostaglandins Leukot Essent Fat Acids. 2012;87(4-5):127-34.

82. Ed Rainger G, Chimen M, Harrison MJ, Yates CM, Harrison P, Watson SP, et al. The role of platelets in the recruitment of leukocytes during vascular disease. Platelets. 2015;26(6):507-20.

83. Elajami TK, Colas RA, Dalli J, Chiang N, Serhan CN, Welty FK. Specialized proresolving lipid mediators in patients with coronary artery disease and their potential for clot remodeling. FASEB J : Off Publ Fed Am Soc Exp Biol. 2016.

84. Dona M, Fredman G, Schwab JM, Chiang N, Arita M, Goodarzi A, et al. Resolvin E1, an EPA-derived mediator in whole blood, selectively counterregulates leukocytes and platelets. Blood. 2008;112(3):848-55.

85. Gong Y, Lin M, Piao L, Li X, Yang F, Zhang J, et al. Aspirin enhances protective effect of fish oil against thrombosis and injury-induced vascular remodelling. Br J Pharmacol. 2015;172(23):5647-60.

86. Mahajan-Thakur S, Bohm A, Jedlitschky G, Schror K, Rauch BH. Sphingosine-1-phosphate and its receptors: a mutual link between blood coagulation and inflammation. Mediat Inflamm. 2015;2015:831059.

87. Vito CD, Hadi LA, Navone SE, Marfia G, Campanella R, Mancuso ME, et al. Platelet-derived sphingosine-1-phosphate and inflammation: from basic mechanisms to clinical implications. Platelets. 2016;27(5):393-401.

88. Pietri P, Vlachopoulos C, Terentes-Printzios D, Xaplanteris P, Aznaouridis K, Petrocheilou K, et al. Beneficial effects of lowdose aspirin on aortic stiffness in hypertensive patients. Vasc Med. 2014;19(6):452-7.

89. Soloviev MA, Kulakova NV, Semiglazova TA, Borodulina EV, Udut VV. Correction of endothelial dysfunction in patients with arterial hypertension. Bull Exp Biol Med. 2011;151(2):183-5.

90. Magen E, Viskoper JR, Mishal J, Priluk R, London D, Yosefy C. Effects of low-dose aspirin on blood pressure and endothelial function of treated hypertensive hypercholesterolaemic subjects. J Hum Hypertens. 2005;19(9):667-73.

91. Hermida RC, Ayala DE, Calvo C, Lopez JE. Aspirin administered at bedtime, but not on awakening, has an effect on ambulatory blood pressure in hypertensive patients. J Am Coll Cardiol. 2005;46(6):975-83.

92. Hermida RC, Ayala DE, Mojon A, Fernandez JR. Ambulatory blood pressure control with bedtime aspirin administration in subjects with prehypertension. Am J Hypertens. 2009;22(8):896-903.

93. Ayala DE, Hermida RC. Sex differences in the administrationtime-dependent effects of low-dose aspirin on ambulatory blood pressure in hypertensive subjects. Chronobiol Int. 2010;27(2): 345-62.

94. Hermida RC, Ayala DE, Calvo C, Lopez JE, Mojon A, Rodriguez $\mathrm{M}$, et al. Differing administration time-dependent effects of aspirin on blood pressure in dipper and non-dipper hypertensives. Hypertension. 2005;46(4):1060-8.

95. Mancia G, Fagard R, Narkiewicz K, Redon J, Zanchetti A, Böhm $\mathrm{M}$, et al. $2013 \mathrm{ESH} / \mathrm{ESC}$ Guidelines for the management of arterial hypertension. Eur Heart J. 2013;34(28):2159-219.

96. Bibbins-Domingo K. Aspirin use for the primary prevention of cardiovascular disease and colorectal cancer: U.S. Preventive Services Task Force Recommendation StatementAspirin Use for the Primary Prevention of CVD and CRC. Ann Intern Med. 2016;164(12):836-45.

97. National Institute for Health and Care Excellence. Clinical Knowledge Summaries. Antiplatelet treatment (Last revised in October 2015). Scenario: Antiplatelet treatment for primary prevention of cardiovascular disease (CVD). Available from 
http://cks.nice.org.uk/antiplatelet-treatment\#!scenario. Accessed August 10, 2016.

98. Santilli F, Pignatelli P, Violi F, Davì G. Aspirin for primary prevention in diabetes mellitus: from the calculation of cardiovascular risk and risk/benefit profile to personalised treatment. Thromb Haemost. 2015;114(11):876-82.

99. Kunutsor SK, Seidu S, Khunti K. Aspirin for primary prevention of cardiovascular and all-cause mortality events in diabetes: updated meta-analysis of randomized controlled trials. Diabetic Med: J British Diabetic Assoc. 2016.

100. Bartolucci AA, Howard G. Meta-analysis of data from the six primary prevention trials of cardiovascular events using aspirin. Am J Cardiol. 2006;98(6):746-50.

101. Baigent C, Blackwell L, Collins R, Emberson J, Godwin J, Peto R, et al. Aspirin in the primary and secondary prevention of vascular disease: collaborative meta-analysis of individual participant data from randomised trials. Lancet (London, England). 2009;373(9678):1849-60.

102. Bartolucci AA, Tendera M, Howard G. Meta-analysis of multiple primary prevention trials of cardiovascular events using aspirin. Am J Cardiol. 2011;107(12):1796-801.

103. Raju N, Sobieraj-Teague M, Hirsh J, O’Donnell M, Eikelboom J. Effect of aspirin on mortality in the primary prevention of cardiovascular disease. Am J Med. 2011;124(7):621-9.

104. Raju N, Sobieraj-Teague M, Bosch J, Eikelboom JW. Updated meta-analysis of aspirin in primary prevention of cardiovascular disease. Am J Med. 2016;129(5):e35-6.

105. Guirguis-Blake JM, Evans CV, Senger CA, O'Connor EA, Whitlock EP. Aspirin for the Primary Prevention of Cardiovascular Events: A Systematic Evidence Review for the U.S. Preventive Services Task ForceAspirin for the Primary Prevention of Cardiovascular Events. Ann Intern Med. 2016;164(12):804-13. A systematic review of effectiveness of aspirin for primary prevention of cardiovascular events.

106. Whitlock EP, Burda BU, Williams SB, Guirguis-Blake JM, Evans $\mathrm{CV}$. Bleeding risks with aspirin use for primary prevention in adults: a systematic review for the U.S. Preventive Services Task Force Bleeding Risks With Aspirin Use. Ann Intern Med. 2016;164(12):826-35. A systematic review of safety of aspirin for primary prevention of cardiovascular events.

107. Bayer. A Study to Assess the Efficacy and Safety of EntericCoated Acetylsalicylic Acid in Patients at Moderate Risk of Cardiovascular Disease (ARRIVE). July 12, 2007. Updated: July 1, 2016. NLM Identifier: NCT00501059 Available from: https://clinicaltrials.gov/ct2/show/NCT00501059. Accessed July 30, 2016.

108. ASPREE Investigator Group. Study design of ASPirin in Reducing Events in the Elderly (ASPREE): a randomized, controlled trial. Contemp Clin Trials. 2013;36(2):555-64.

109. De Berardis G, Sacco M, Evangelista V, Filippi A, Giorda CB, Tognoni G, et al. Aspirin and Simvastatin Combination for Cardiovascular Events Prevention Trial in Diabetes (ACCEPTD): design of a randomized study of the efficacy of low-dose aspirin in the prevention of cardiovascular events in subjects with diabetes mellitus treated with statins. Trials. 2007;8:21.

110. Aung T, Haynes R, Barton J, Cox J, Murawska A, Murphy K, et al. Cost-effective recruitment methods for a large randomised trial in people with diabetes: A Study of Cardiovascular Events iN Diabetes (ASCEND). Trials. 2016;17(1):286.

111. Population Health Research Institute. The International Polycap Study 3 (TIPS-3). July 10, 2012. Updated: May 22, 2015.
Available from: https://clinicaltrials.gov/ct2/show/NCT01646437. Accessed July 28, 2016.

112. Le Quellec S, Bordet JC, Negrier C, Dargaud Y. Comparison of current platelet functional tests for the assessment of aspirin and clopidogrel response. A review of the literature. Thrombosis Haemostasis. 2016(2016-07-21 00:00:00).

113. Krasopoulos G, Brister SJ, Beattie WS, Buchanan MR. Aspirin "resistance" and risk of cardiovascular morbidity: systematic review and meta-analysis. BMJ. 2008;336(7637):195-8.

114. Snoep JD, Hovens MM, Eikenboom JC, van der Bom JG, Huisman MV. Association of laboratory-defined aspirin resistance with a higher risk of recurrent cardiovascular events: a systematic review and meta-analysis. Arch Intern Med. 2007;167(15):1593-9.

115. Pettersen AA, Arnesen H, Seljeflot I. A brief review on high onaspirin residual platelet reactivity. Vasc Pharmacol. 2015;67-69: 6-9.

116. Nagatsuka K, Miyata S, Kada A, Kawamura A, Nakagawara J, Furui E, et al. Cardiovascular events occur independently of high on-aspirin platelet reactivity and residual COX-1 activity in stable cardiovascular patients. Thrombosis Haemostasis. 2016;116(2).

117. Brun C, Daali Y, Combescure C, Zufferey A, Michelson AD, Fontana $\mathrm{P}$, et al. Aspirin response: Differences in serum thromboxane B2 levels between clinical studies. Platelets. 2016;27(3):196202.

118. Homorodi N, Kovacs EG, Lee S, Katona E, Shemirani AH, Haramura $\mathrm{G}$, et al. The lack of aspirin resistance in patients with coronary artery disease. J Transl Med. 2016;14:74.

119. Freynhofer MK, Gruber SC, Grove EL, Weiss TW, Wojta J, Huber $\mathrm{K}$. Antiplatelet drugs in patients with enhanced platelet turnover: biomarkers versus platelet function testing. Thromb Haemost. 2015;114(9):459-68.

120. Kakouros N, Nazarian SM, Stadler PB, Kickler TS, Rade JJ. Risk factors for nonplatelet thromboxane generation after coronary artery bypass graft surgery. J Am Heart Assoc. 2016;5(3), e002615.

121. Christensen KH, Grove EL, Wurtz M, Kristensen SD, Hvas AM. Reduced antiplatelet effect of aspirin during 24 hours in patients with coronary artery disease and type 2 diabetes. Platelets. 2015;26(3):230-5.

122. Henry P, Vermillet A, Boval B, Guyetand C, Petroni T, Dillinger $\mathrm{JG}$, et al. 24-hour time-dependent aspirin efficacy in patients with stable coronary artery disease. Thromb Haemost. 2011;105(2): 336- 44.

123. Larsen SB, Grove EL, Neergaard-Petersen S, Wurtz M, Hvas AM, Kristensen SD. Determinants of reduced antiplatelet effect of aspirin in patients with stable coronary artery disease. PLoS ONE. 2015;10(5), e0126767.

124. Doroszko A, Szahidewicz-Krupska E, Janus A, Jakubowski M, Turek A, Ilnicka P, et al. Endothelial dysfunction in young healthy men is associated with aspirin resistance. Vasc Pharmacol. 2015;67-69:30-7. A study showing association between endothelial function and effectivenes of aspirin therapy.

125. Larsen SB, Grove EL, Wurtz M, Neergaard-Petersen S, Hvas AM, Kristensen SD. The influence of low-grade inflammation on platelets in patients with stable coronary artery disease. Thromb Haemost. 2015;114(3):519-29. A study showing impact of vascular inflammation on platelets aggregation.

126. Stratz C, Nuehrenberg T, Amann M, Cederqvist M, Kleiner P, Valina CM, et al. Impact of reticulated platelets on antiplatelet response to thienopyridines is independent of platelet turnover. Thrombosis Haemostasis. 2016(2016-08-04 00:00:00). 